\title{
Sustainable Mountain Tourism Development in Khumbu Region
}

\author{
Chanakya P. Rijal*
}

\begin{abstract}
As a result of highly impressive socio-behavioral temperament and character of the Sherpas in the eastern mountains, many people may be influenced to visit Nepal again and again and the outcome could be the spread of global brotherhood of the Nepalese people. The Sherpas are regarded as the symbolic source of inspiration by means of their simplicity of living, grounded religious and spiritual faith and trustworthiness - all contributing in an experiential living in the Himalayas. This article presents with an exploration of the problems, challenges and prospects for promoting sustainable mountain tourism keeping the Hilarity of the Sherpa Spirit at the center of concern while establishing aworldview on sustainable tourism development and supplementing it with the grounded multiple realities via ethnographic dialectics.
\end{abstract}

Keywords: Sustainability and sustainable tourism, goals of sustainable tourism, pillars of sustainable tourism, Sherpa Hilarity and Sherpa spirit.

This work has explored sustainable tourism as an instrument to accomplish a twofold objective of any business -- for achieving the fulfillment and innovation by means of formal and informal organizational initiatives. The informal practices affect the values and behaviors, whereas the formal ones establish rules and procedures required for the innovation and task accomplishment.

It has been identified that sustainability is built on a select principles that are grounded with environmental, economic and socio-cultural aspects of development. This exploration attempts to confirm that the hilarity and working spirit of the people in a locality, accompanied by optimal use of environmental resources, promotion of socio-cultural authenticity of the host communities, focused economic operations and community-wide shared commitment serve as the building blocks of sustainable tourism development in any context.

\footnotetext{
* Dr. Rijal is a freelance researcher cum development strategist and also has depth involvement in teaching for higher education at different universities and colleges. Currently, he has been involved in working in the areas of sustainable mountain tourism through entrepreneurship development with specific focus on Khumbu Region of Nepal and teaches at Nepal College of Management, Dhobighat, Kathmandu Unversity.
} 
"I wish, the enactment of federalism in the country will bring back our wish and dream of promoting the Khumbu Region as a symbol of pure tourism for adventure, pilgrim and spiritual learning for rest of the world; by then there will be many attractions built in our areas -- even in isolated and distant villages so that the tourists will extend their stay in the communities; there will be more jobs and earning for our people, especially the poor ones", shared the key participant at Khumjung Valley.Yes, the people of this region are waiting desperately for good days to come. And, sustainable mountain tourism could be promoted with several evidence-based practices to generate economic viability, local prosperity, local employment, social equity, visitors' fulfillment, local control, community wellbeing, cultural richness, physical integrity, biological diversity, efficient development and consumption of resources, and environmental purity.

Methodology of works: As part of qualitative investigation, this work has been primarily based on an extensive review of existing literature in the area of interest that includes the works on Sherpa character and insights on sustainable mountain tourism development. Further, the work has been supplemented by the help of a single key participantshared insights produced in the form of an ethnographic dialectics. In addition, as the present researcher has been closely working in the Khumbu Regionsince last five years, a lot of self- experiential learning-based information has been used. The total makeover of this work has involved at least four visits in this region since last five years, each visit consuming a stay and working period of minimum tendays. This article is not the final outcome of the ongoing work. It is rather, an initial part of qualitative inquiry.

Rationale of the work: The idea of writing this article as a link to learn about promoting sustainable tourism development in the Khumbu Region came into existence as a result of present researcher's continued interest and commitment to work closely for the promotion of Nepalese tourism and also as a gratitude to the commitment of the Sherpasof Nepal, who in fact, have contributed to the immeasurable extent to make Nepal and her culture, tradition and value systems better known in the world context. This work has been expected to serve as an integrated source of learning for various concerned agencies including the students, higher education teachers, explorers, national and international policy makers, and many others.

Qualification of the key participant: The key participant of this exploration is a legitimate Sherpa-- born, grown, living and working at the Khumjung Valley, the heart of the Khumbu Region. This is a gentleman on his late fifties. He runs a village resort. He has an extensive travel exposure of the nation, and the world at large. His contribution on development, protection and promotion of Sherpa land culture, tradition, value systems and nature conservation has been widely regarded by all stakeholders in the region. Therefore, the present researcher firmly believes his responses would be closer to the grounded reality-based truth. The present researcher firmly believes this participant as one of the most legitimate representative sources for learning about the hilarity of the Sherpas. 
Meaning of the thematic constructs: Sustainable mountain tourism development is the key thematic construct of this article. It is quite relevant to refer more authentic institutional insights onto it before going through the article. For this, the present researcher found the insights of United Nations Environment Program and United Nations World Tourism Organization ([UNEP, \& UNWTO], 2005), which state sustainable tourism as - the tourism that takes full account of its current and future economic, social and environmental impacts, addressing diverse needs of the visitors, industry, environment and host communities. It has been further stressed that the principles of sustainability refer to the environmental, economic, and socio-cultural aspects of tourism development -- all focused to maintain a suitable balance between these three dimensions to guarantee a long-term prosperity.

Basically, sustainable tourism aims to - 1. make optimal use of environmental resources that constitute the key elements in tourism development, maintaining essential ecological processes and helping to conserve natural heritage and biodiversity, 2. respectthe socio-cultural authenticity of the host communities, conserve their built and living cultural heritage and traditional values, and contribute to inter-cultural understanding and tolerance, and finally, 3. ensurefor viable, long-term economic operations, providing socio-economic benefits to all stakeholders that are fairly distributed, including stable employment and income generating opportunities and social services to the each host community, and contributing to poverty alleviation (UNEP, \& UNWTO, 2005).

It has been vigorously emphasized that achieving sustainability in tourism is a long-term, continuous proposition of development that requires the informed participation of all relevant stakeholders with strong backing from the national and internal formal and structural systems including politics as well as general structural governance systems to ensure wider participation and consensus building.

As part of continuous process, it also requires constant monitoring of impacts, introducing the necessary preventive and/or corrective measures whenever necessary. At the same time, sustainable tourism is also aimed at maintaining a high level of tourist satisfaction by ensuring meaningful experiencesfor the tourists, raising their awareness about sustainability issues and promoting sustainable practices amongst them.

Similarly, Sherpa Spirit'another equally important thematic construct used in this article, may be referred to as the holistic and value-driven way of the Sherpa life, which is governed by their religion, especially the Tibetan Buddhism and belief on spiritualism - a supernatural power of forces the sinless people possess, as the Sherpas believe (Kunwar, R. R., 2014; depicted from a personal discussion with the present researcher; \&Klatzel, 2009). Further, the present researcher would like to recall the term 'hilarity' as the gaiety or jollity of the Sherpa people as a source of inspiration to the rest of people(Klatzel, 2009). 
About the researcher: ChanakyaP. Rijal holds a PhD degree in Leadership from Kathmandu University, Nepal after obtaining an MBA degree from Maastricht School of Management, The Netherlands. DrRijal has earned several diplomas specializing in corporate communications, institutional governance, computing, strategic thinking, and teaching pedagogies. In his career span of about 25 years, he has an extensive experience of establishing and promoting a number of successful education institutions in Nepal. He has worked for teaching right from pre-primary to doctoral levels, worked for establishing the national policies and relevant benchmarks on research and quality assurance and accreditation, worked as a freelance expert for research and innovation, professional development, social welfare initiatives and academic writing. DrRijal also holds proven expertise in systems thinking for holistic development. He has executed many assignments with specialization in project planning, implementation, monitoring and evaluation, sustainable development, new business development and truthful branding of products and services. DrRijal can be reached viarijalcpr@gmail.com.

\section{Preamble}

The mountain tourism is synonymous to adventure travel and it is one of the fastest growing but least understood forms of international and intercultural tourism product mix. Its role in the economic development of remote places and impact on local society, economy, and the environment has not fully been comprehended, eventhough it has been adoptedenthusiastically by many third-world nations from the perspectives of long-term sustainable development and promotion of tourism as it is also considered a metaphor to learning cross-cultural andsocial practices. Mountain tourism is widely known as experience economy which defies the norms of traditional commodity exchanges (Zurick, 1992, \& Jack, \& Phipps, 2005) and it requires a deeply touching 'effect' to confirm a more sustainable future.

Building on core-periphery of tourism theory, Zurick(1992) has proposed an adventure travel spatial-linkage model with an aim to connectNepal's remotefrontiers with the globaltourism economy. The model confirms that the adventure tourists movethrough a hierarchy oftravel gateways beforereaching adventure destinations, mostly locatedin isolated, subsistence population areas. Thismovement produces a unique structure of tourism space that in turn, contributes to theformation in Nepal of regional developmentssuch ashilltowngateways, hinterland tourismdestinations, and multi-use parklands. This scholar has also suggested with an adventure tourism impact model to address the tourism related problems associated with exceedingsocial andenvironmental carrying capacities. In addition, the model includes more positive impacts linked to converging the interests of Nepal's national economy, indigenous populations, tourists, andconservation development works. Of course, with its steady growth, adventure tourism in Nepal will playan increasingly important role for national andlocal development in the frontier areas but it equally requires closer attention for confirming the sustainable conservation and promotion of such destinations. 
The World Tourism Organization ([WTO], 2005) has pointed out tourism as an activity that has grown by around 25 percent globally in the past 10 years, right from late 1980s to late 1990s, by holding almost 10 percent of the world's economic activity and also a major generator of the employment worldwide.McMinn (1997) also agreed on this reality and stated that tourism is the world's largest industry as it employs one out of each nine employees with approximately 6 percent of the global gross national profit (GNP) generation whereby it has served as a panacea for the third-world countries to resolve their numerous socio-economic problems.At the same time, it is observed that tourism, especially the mountain tourism,also has critical impacts on natural and built environments and on the wellbeing and culture of host populations(McMinn, 1997). Thus, it requires closer attention from the sustainability point of view.

WTO (2005) revealedthat the concept of systematic approach to sustainable tourism development commenced in around 1980s and today it has become one of the major focuses of each member state and respective community globally as the way to a better future whereby the governments, respective communities and other immediate beneficiary stakeholders are made more responsible and accountable in this noble mission. There are many advocacies that the policies to promote sustainable development should take full account of the opportunities offered by the tourism.

On the other hand, it is a bitter fact that Nepal cannot be promoted as a high consumption, industrial production destination. So, there is an immense need of an assessment to identify and cash on what the country is better off. Apparently, as gifted by the nature, Nepal may have tremendous potential for at least three sectors - tourism, agriculture and hydropower (Rijal, 2014). So, the national developmental emphasis must be on effective promotion of these three sectors and the national developmental and industrial priorities must address the issue of sustainable development and promotion of these nature gifted sectors.

Also from the perspective of sustainable resource management, production and marketing, these sectors may have higher advantage. According to Chowdhury (2013), more than 1 million tourists visiting to Nepal annually have daily per capita spending of above US \$ 100. Since the country is regarded as one of the authentic and ethnic tourism destinations, it has witnessed itself as one of the foreign direct investment (FDI) and power surplus nations in the world. As a result, tourism in Nepal has become a point of attraction for the global investors. In fact, tourism may be promoted as an integrated element for the promotion of water and agricultural prospects too, visualizes (Rijal, 2014).

Sustainable development is an old concept but has received high emphasis these days in every sector globally. It re-emerged in the 1960s, as global economic growth gathered speed after World War II. In 1980 the International Union for the Conservation of Nature (IUCN) based in Geneva, issued the World Conservation Strategy and 
brought the cautious and sometimes negative thinking of the conservationist approach to development and with the positive but sometimes heedless world of the developer. It set the stage for the publication of the Brundtland Report of 1987, a work created by the World Commission on Environment and Development (WCED), and the work from which most of the current thinking on sustainable development stems as the development that meets the needs of the present without compromising the ability of future generations to meet their own needs. In 1992, at the Earth Summit in Rio de Janeiro, sustainable development became a globally agreed agenda by the nations of the world (Lane, 2014).

Sustainable tourism development has to be promoted as a holistic means of prosperity social footed with at least four principles -1 . integration of the ideas of holistic planning, cross-sectoral planning and strategy making, 2. emphasis on importance of preserving essential ecological processes, 3 . need to protect both human heritage and biodiversity, and 4. requirements that development should be carried out such that the productivity does not deplete resources for the long-term, future generations. In the present Nepalese context, the same principles may be directly applicable for mountain tourism development.

All what Nepal requires now includes a long-term shared vision, national commitment, public-private collective efforts, and defined priority of the country on its agenda of tourism development, especially for mountain tourism. Availability of the best training

and education system, leveraged transportation facilities and widened communication systems serve as the key infrastructure required for the overall development of a destination (Chowdhury, 2013).

In fact, very fast development of China, South Korea, Singapore and HongKong are the best examples of such transformation in Asia by promoting these three drivers of socio-economic development (Rijal, 2014). Among these three requisites too, the development of tourism should be regarded as the primary driver as it would leverage the wisdom, liberation, envisioning, empowerment, commitment, conceptual and technical competence and leadership strength required for ideation, planning, development and promotion of rest of sectors, making Nepal a lovely destination for the world of travelers.

\section{The Sherpa Hilarity and Sustainable Tourism Development}

As it applies to the personal observation of the present researcher, the naturally grounded personality disposition, serving spirit with focused mindset, religious and traditional valuesystem and cultural practices are a few of the loving characteristic features of the Sherpas in the Khumbu Region of Nepal that might have influenced many people working for at least something related to them. In fact, once the visitors are served by the Sherpasof this region, such visitors love to come back again and again. 
As a symbol of their gaiety, one of the most important characters Sherpasin hospitality, a visitor must not leave the house unfed or without a drink, shared the key informant of the present researcherat Khumjung Valleyduring a two-day discourse on Sherpasof the mountains in Nepal. It is quite apparent learning in the region that the guests are often offered with the Tibetan tea or home-made wine as part of welcoming ritual in the locality. The visitors of high standing profiles will be served a snack, or even a complete free meal, if a Sherpa offers it free; it must be accepted as freesolace as it is offered by heart. Even the offerings at the cost of visitors do trace a complete solace of Sherpa spirit so that the customers feel just like service by soul. Such a behavior might have been linked with their spiritual value system as the Sherpas of this region have a belief that the people having evil thought about others would negatively affected by the negative waves of 'spirit'. For example, Kunwar (1999) in a scholarly work entitled "Fire of Himal: An Anthropological Study of the Sherpas of Nepal Himalayan Region", has recognized the religious and spiritual footage of the Sherpa behavior and their cognition to represent an authentic Nepalese tribe that has capacity and reason of being a source of inspiration for learning about human values.

Kunwar (1999) has performed a depth, multi-fold, cultural-anthropological and social systems diagnoses of the overall value systems, language, traditions, religion, economic subsistence, behavior of human settlements, and geo-biodiversity-based learning about the Sherpas and overall livelihood in the region - all presented in the form of an ethnographic narrative. This scholar has observed closely the Sherpa religion and spirituality right from its evolution in the region. This is one of the best works to explain the Sherpa hilarity and meaning of 'fire' in a true sense.

Other source of creation of hilarity in this community is that the guests in Sherpa homes have complete access to both the kitchen and the area set aside for worship. 'Such a practice results in creation of brotherhood with the visitors', shared the key participant after the morning tour of the valley. In fact, the Sherpas are quite open for experiential learning with them in many respects.

A more recent work on Hilarity of Sherpa Spirit came into realization of the present researcher as a result of present researcher's little understanding and knowledge of gaiety of spirit of the Sherpasin the Khumbu Region. The present author firmly believes that Sherpa Hilarity in Khumbu Region of Nepal is the biggest link to the success of each endeavor targeted to sustainable development in the great Himalayan glacier made heavenly region. Klatzel (2009) has noted that the world has been influenced heavily by rich cultural heritage of Sherpas, especially in the Khumbu Region of Nepal.Yes, Sherpa culture is very much important and worth learning, especially for those who are interested to learn about different cultural paradigms in the Himalayan region. More importantly, Sherpa culture and tradition on caring the guestsserves as a source of natural learning about the work, life and deeds attached approach to execute the eastern methodology of 'Atithi Devo Bhawa' meaning -- may the guest be treated as the God. 
The natural environment itself serves as one of the key sources of survival for the Sherpas in the Great Himalayas. As almost all the region has been situated within the buffer zone of Sagarmatha National Park, preserving nature, natural beauty and natural inhabitants and plants has been regarded as an important responsibility exhibited by the Sherpas in the region. Maintaining the quality of human and rest of natural life,making sure that the visitors understand their responsibility on conservation, and at the same time, providing with world class hospitality services to each visitor has been observed to be the marvelous job performed by the Sherpas. And this is what the present researcher intends to project as the outcomes of the Sherpa Hilarity and Spirit.

Surprisingly, though these people are less educated in terms of formal education, they render with such a high quality service and their living itself proves as one of the world class best practices. May be, it is because each member in the Sherpa society respects the value of the 'spirit' they have faith on (Kunwar, 1999), and is equally concerned about the consequences of failure to abide by the power of such a spirituality.

However, everything cannot continue moving smooth and clear on its own as expected forever. It needs be timely and adequately nourished to safeguard its sustainability with lasting future prosperity. In this work, the present author has attempted to explore a number of areas alarming for the sustainability of the Hilarity of the Sherpa Spirit as one of the national assets of Nepal tourism.Newssome et al. (2002, as cited in Raasch, 2004) indicated that as the nature-based tourism occurs in the natural setting, it may require more efforts to fostering adequate understanding and conservation of the natural environment by means of an eco-centric philosophy whereby the natural environment continues to serve as a platformfor learning about the society. In this respect, the people in the Khumbu Region of Nepal also seem to be in need of tangible support and protection in their mission to promote tourism and natural life in Himalayan region.

Sustainability, in any context, may be referred to as a holistic composition of development with more viable, resilient, quality focused, futuristic and needs-based approaches to promote empowerment and ownership, and at the same time, it continues to embrace local, regional, national and international integration of the values, concerns and priorities.Sustainable tourism, on the other hand, can be defined as a service consuming the optimal use of social, natural, cultural and financial resources in an equitable and self-sustaining basis to provide a unique visitor experience and an improved quality of life promoted in partnership with the government, the private sector and other national and international communities. For example, United Nations Organization(UNO, 1992), on its international conference on environment and development, has stated -

Humanity stands at a defining moment in history. We are confronted with a perpetuation of disparities between and within nations, a worsening of poverty, hunger, ill health and illiteracy, and continuing deterioration of the ecosystems on which we 
depend for our well-being. However, integration of environment and development concerns and greater attention to them will lead to the fulfillment of the basic needs, improved living standards for all, better protected and managed ecosystems and a safer, more prosperous future. No nation can achieve this on its own; but together we can - in a global partnership for sustainable development (Agenda 21; Chapter 1; Preamble 1.1).

The conference passed with emphasis a number of resolutions with an aim to accelerate international cooperation for sustainable development in the developing countries and related domestic policies on combating poverty, help changing consumption patterns, empowering demographic dynamics on sustainability, protecting and promoting health conditions and human settlements, and integrating the issues of environment and development (UNO, 1992). The resolution emphasized the protection of atmosphere and land resources, combating deforestation, managing fragile ecosystems and many other concerns of sustainable environmental development as the global concerns for the conservation and its management as common means of global sustainable development of environment. The conference firmly recognized the reasons and ways how the women, youth and indigenous people and their communities could be involved in the global mission of environmental protection and development.In fact, environmental sustainability is the backbone of tourism sustainability (Kunwar, 2010; \&Klatzel, 2009) as it promotes the ecosystem and ecotourism, which are one of the core concerns of the visitors of any place.

Similarly, sustainable development is the act of meeting the development needs of the present without compromising the requirements and ability of the future generations of humanity and institutions to meet their needs (World Commission on Environment and Development [WCED], as cited in Kunwar, 2010).

The United Nations World Tourism Organization ([UNWTO], 1996; as cited in Castellani, \&Sala, 2009)has definedsustainable tourism as a development initiative that leads to management of all resources such a way that the desired socio-economic and aesthetic needs can be accomplished while maintaining cultural integrity, essential ecological and biological processes and diversity, and creation and promotion of valuable life support systems without hampering the existing supernatural systems and subsystems. Sustainable tourism responsively takes full account of current and future socio-economic as well as environmental impacts while delivering the needs of the visitors, industry, local environment and the host communities. The concept is universal and may apply equally in all parts of the world for each sector.

In Nepal, specifically in the eastern high hills and mountains, the main concern for emphasizing sustainable tourism serves multi-fold purposes. The nation is at a cross-road to ensure adequate and appropriate national capacity to manage the tourism sector. It has to continually improve the tourism marketing mix in light of emerging global trends. Time and again, the nation has been forced to develop efficient and 
cost effective transportation options to facilitate adequate destination accessibility. At the same time, the nation also has to ensure the sustainable use of natural environment and cultural heritage for the benefit of wider spectrum of the society and beyond. For this, it is equally important to develop and strengthen the links between tourism and other sectors nationally and globally. Also it is equally imperative to manage the health, safety and security issues that impact the long-term outcomes of tourism as one of the key sectors of national economic development.

In this respect, mountain tourism in Nepal needs be strengthened keeping in view at least a three-pillar philosophy - economic, social and environmental pillars to confirm its sustainability (National Planning Commission [NPC], 2012).Principally, sustainable tourism development requires not only improved general and mass marketing, but it also requires creation and promotion of more effective niche markets, enactment of relevant rules and regulations, optimal use of environmental resources in tourism development, maintain essential ecological processes and help to conserve natural resources and biodiversity (Rijal, 2014).Sustainable forms of tourism should respect the socio-cultural authenticity of the host communities, conserve their built and living cultural heritage and traditional values, and contribute to the inter-cultural understanding and tolerance. Tourism also contributes to improving the quality of life with meaningful, wider participation that results in lasting beneficial effects to the communities.

In fact, sustainable tourism attempts to confirm more viable, long-term economic operations, providing socio-economic benefits that are fairly distributed to all the stakeholders by means of stable employment and income generation opportunities. There is no single model for the implementation of sustainable tourism. Instead, a mix of right management practices, appropriate legislative instruments and right forms of partnership are needed, depending on the given situation.

More importantly, the KhumbuRegion, as a key tourism destination, has its own features, assets, problems and vulnerabilities which may be completely different from that of other such destinations.Klatzel (2011) has observed a number of such distinctions in respect with Sherpa language, occupations, food and clothing, housing and décor, customs and religion in the Khumbu region - these all may be considered as the aspects aligned to the idea of Sherpa Hilarity for sustainable tourism promotion.

\section{The Quest of Learning}

As a trainer and university level educator in the field of hospitality management sciences, the present scholar has been always concerned to explore the problems and prospects of promoting this very special sector of national socio-economic development in Nepal. In this respect, the researcher has attempted to give continuity to years' long journey of exploration about the Sherpas of the Khumbu Region of Nepal. In this article, the present researcher has attempted to explore the problems and prospects 
of promoting sustainable tourism in the Khumbu Region in light with Hilarity of Sherpa Spirit from different respects of sustainable mountain tourism development in this very special touristic destination of the country.

This article provides a brief account of content information on sustainability with specific attention to hospitality and tourism industry and introduces the concept of sustainability that may be of useful in hospitality and tourism education and training. The present researcher expects that it should serve instrumental to its readers to identify relevant themes in sustainable mountain tourism management in a variety of hospitality related sectors including the management of resources, issues pertaining to conservation and continuation of typical regional traditions and cultures.

The present researcher was much interested to uncover the different facets attached with the issue of sustainable tourism promotion in the KhumbuRegion by means of a more qualitative discourse to be substantiated by grounded facts collected through an ethnographic dialectics on multiple realities which could be triangulated by the help of depth personal field observation and extensive review of existing literature related to the concern of the present inquiry.

\section{Evolution of Memorable Stage}

Many scholars have attempted project the evolution of services as the source of evolution of service economy. For example, Rijal (2014), Keelson (2012), and Kotler and Armstrong (2009) have pointed that the early era of industrial revolution between mid-eighteenth century to its end the overall focus of the industry was on 'production' concept as there were only a few firms producing the commodities to meet the demand of the total population of the world. Thus, mass production was considered as the most feasible concept in those days.

As the time passed, such a situation influenced more people, governments and other institutions to come into the world of business in early 1900s to till 1950s and the competition emerged among the firms and gradually resulted in evolution of competition imperfection. It forced industry's 'production orientation' to be added with 'product orientation' as the public and private enterprises perceived that mass production alone was not enough to address the growing competition. By then, the customers and consumers had become choosy and product quality was already considered as a means of cross-product comparison. Thus, the focus on product concept emphasized quality orientation of the firms and the product quality became the means of fighting in competition, which ultimately added onto the increasing level of quality consciousness among the firms and consumers.

Then after, gradually, emerged a series of philosophies including selling concept, marketing and communications concept, customer orientation, societal marketing concept and finally, the holistic marketing concept till reaching to the early twenty first century. 
Another beauty of evolution of these concepts is that in each stage of evolution, the newer concepts evolved as an additional, supplementary concept to earlier existing concepts. As a result, the entire philosophy of managing the world of business could flourish. On the other hand, such a development over time pushed up the transformation of traditional four Ps (product, place, price and promotion) of the marketing mix elements into 7 Ps (product, place, price, promotion, people, processes, physical evidence of operations) in a more service dominated economy, again as a supplementary thematic evolution of business (Rijal, 2014; \&Loveluck, Wirtz, \& Chatterjee, 2011) and service became an integral component of each type of business.

In the discourse of the present day business world, it has been found to be benefitted significantly as a result of emergence of a highly noble concept of transforming the diversity of services within tangible classifications and tourism has emerged as one of the globally recognized sources of business priorities. Tourism has been considered as one of the purest forms of experiential economy worldwide. For example, Pine and Gilmore (1998) have defined 'experience economy' as the final phase of an economic progression to mark the early twenty first century. As it has been discussed earlier, it evolved through the phases of commodities, goods, services economies, and finally stage of memorable experience of the services received.

In fact, experience economy applies equally to all sectors of business. Say, for example, an automobile retailer would like to serve with an impression to create a realization of being at the helping hands. Similarly, the customers of a retail stores should feel being cared of their product needs. An airline's passengers should get to be exposed with a safe, comfortable and welcoming journey, and similar should be the memories of travelers to a destination after their journey is over. These are a few examples of experiences - the memories of the felt wellbeing.

Further, pioneering in their work on 'experience economy' Pine and Gilmore (1998) have presented this concept as the 'stage' function of economy. In their proposition, the scholars have presented experience as an economics' role and it has been claimed that the nature of offering is memorable in experiential service economy. Such a memory is attached with the 'personal attributes' of the beholder of memory on received services. The method of supply of service is revealed over a period of time on full realization or recollection of experience. The seller plays a role of stager. The buyer acts as a guest whereby the perceived sensation serves as the factors generating demand. The assumption is that better service delivery may generate positive sensation on services delivered. In other words, it is a real perception made by the consumer after having experience of the marketing offerings (Rijal, 2014).

In tourism, all what the firm sells is the experience and retention of the customers and their positive referrals to other prospects partly depends on the experience the firm is able to generate among the past customers. Finally, experience economy may be referred to as an integral component of tourism business as the sole business is 
focused on imparting in customers the life term experiences with positive memories. Thus, it may be noted that higher the degree of positive experience of the services delivered, higher would be the prospect of business sustainability of such an offering.

\section{The Goals of Sustainability and Ways Out}

Sustainability may be considered as one of the tools to achieve organizational success. For example, United Nations Global Compact-Accenture CEO Study (2010, as cited in Bertels, Papania, \&Papania, 2010) identified a two-fold objective of sustainability as emphasized by almost 93 percent of the Chief Executive Officers (CEOs) participating in the study. It was widely reported that sustainability was initiated for achieving the 'fulfillment and innovation' by means of formal and informal organizational initiatives.

These scholars could explore 'fulfillment' as the practices for delivering the current sustainability commitments and 'innovation' as the means that move the organization further along the path to sustainability. On the other hand, these scholars also could explore that the informal practices affect values and behaviors, whereas the formal practices establish rules and procedures required for the innovation and task accomplishment.In fact, the extent of an organization's success will partly depend on the extent to which it cherishes the attainment and innovation through its formal and informal means of operation.

The present researcher firmly believes that this concept may equally apply for the sustainable development of a community too. Thus, the prospects and problems of sustainable tourism development in the Khumbu Regionshould be observed from these two perspectives - fulfillment and innovation - and two approaches - formal and informal. And the key tasks associated in this mission, as suggested by Bertels, Papania and Papania (2010), should include clarifying the expectations, taking initiatives for capacity development for change, building momentum for change and fostering continued and shared commitment for transformation. The idea is quite similar to the philosophical insights of Rijal (2011) as this scholar has suggested at least six philosophical insights for a more sustainable institutional development leading to total quality management (TQM) process climate. The identified initiatives include total participation, customer focus, system standardization, shared commitment, continuous improvement and compliance with the macro-environmental systems development as the philosophical roots of a high quality organizational process climate.

\section{The Pillars of Sustainable Mountain Tourism Development}

Sustainability principles refer to the environmental, economic and socio-cultural aspects of tourism development, and a continued balance must be established between these three dimensions to guarantee its long-term sustainability. Shared commitment may have greater influence on sustainability of the three pillars. 
The key participant at KhumjungValleyalso revealed a number of grievances on the grounds of sustainability. The participant argued with the proof on lack of adequate commitment and accountability from the government's side despite the fact that each account of revenue collection from tourism in this region was directed towards the state's treasury fulfillment. The participant questioned whether it was a responsibility as well as accountability to spend at least a share of such funds for the sustainable development, promotion and maintenance of such touristic destinations for which the visitors pay a large amount of revenue in different forms of accounts to the nation.

Practically, sustainable tourism development must be initiated with optimal use of environmental resources that constitute a key element in tourism development, maintaining essential ecological processes and helping to conserve natural resources and biodiversity. Similarly, respect of socio-cultural authenticity of the host communities, conservation of their built and living cultural heritage and traditional values, and contribution to inter-cultural understanding and tolerance also play important roles. Equally important is to ensure viable, long-term economic operations by providing socio-economic benefits to all stakeholders that are fairly distributed, including stable employment and income-earning opportunities and social services to host communities, and contributing to poverty alleviation. And finally, sustainable tourism may not sustain unless the concerned agencies are able to make it a common mission with shared commitment for development (Rijal, 2011; Bertels, Papania, \& Papania 2010; \& Kunwar, 2010).

Somehow, the present researcher could observe lack of knowhow on local branding and promotion of locally available input based food and beverages (F\&B) items in the region. As a result, a significant volume of revenue generated through F\&B services was being pumped out from this region. Timely and adequate focus on such an idea could serve as a new dimension in this philosophy.

In a more recent work, a scholar has provided with a number of explicit guidelines and principles of sustainable tourism development (Kunwar, 2010) with emphasis on total participation, stakeholder involvement and cooperation from within and beyond the community, local ownership and business linkage within and beyond the community, focus on sustainability of the key resource base and respective community goals, joint-effort on capacity development, shared accountability and task responsiveness, mass training and development of the respective agencies involved, and positioning it as a pure means of overall development of the region.Apparently, these ideas are rooted with the ideas shared by early scholars advocating in the evolution of various marketing concepts as discussed earlier in this article.

Neto (2003) has concluded that new approaches to sustainable tourism development in the developing states need not only seek to minimize the local environmental impact, but also should give greater priority to community participation and poverty reduction with more emphasis on 'pro-poor tourism' approach at both national and 
international levels. Another scholar has emphasized that the principles of sustainable tourism development be composed of environmental, economic, and socio-cultural aspects linked to the target place (Schorner, 2011). Similarly, Thierstein and Walser (2000) have identified as many as five thematic components of coverage of the sustainable tourism development which include rationalization of environment, economy, society, processes and ethical perspectives.

The key participant of the present researcher at Khumjung Valley feared if the national and international agencies and the local communities advocating sustainable mountain tourism in the region were firm enough to consider such thematic components as the integral elements of 'common focus' to give it a systems' approach to sustainability. However, the key participant agreed the relevance of consideration of these elements as part of holistic approach by saying, "I do not see anything more than this to be considered, though I have little knowledge about these talks of you, the more educated people." He meant to confirm the relevance and completeness of the thematic coveragewhile addressing the issues concerned to sustainable tourism development in the region. He further added, "I can work with you with guarantee of support from our Sherpa people to promote the Sherpa spirit with prays for this, but I cannot guarantee for the positive attitude of the park people, neither that of other national and international non-government agencies. One thing, for sure, the government's approach cannot be predicted as we have very much bitter experience of receiving its support in the past when the community was in severe need." It confirms the commitment of the local community but at the same time it also indicates...the problem may be rooted beyond the local society here.Ultimately, may the Sherpa Hilarity win the mission for such a genuine purpose!

"I wish, the enactment of federalism in the country will bring back our wish and dream of promoting the Khumbu Region as a symbolic destination of pure tourism for adventure, pilgrim and spiritual learning for rest of the world, and by then, there will be numerous points of attraction built in our areas, even in isolated and distant villages so that the tourists will extend their stay in the communities and there will be more jobs and earning for our people, especially the poor ones", shared the key respondent.

Naturally, the earner benefits the first and the most. Here, the Khumbu Region is the earner and it must receive the benefits out of its earning the first - it is all about 'the first earner should get the first benefits. It is a universal norm and the situation may turn dangerous if timely addressing fails in this issue.Khumbu Region is a great earner of foreign revenue for Nepal and Nepal must take care of it for a more sustainable development and prosperity of its people and the natural setting at large. That is clear from the verse of the key participant too. It is, indeed, a great lesson for us and we the learners of federal democratic economic policies must pay respect to this concern. 


\section{The Aims of Sustainable Mountain Tourism Development}

The learning insights from different sources in this respect reveal that every mission with development focused initiatives must have a number of defined aims to be attained. For example, Korèekovã, Pasca, and Rouby (2011) have performed a closer review from at least five different approaches to sustainable mountain tourism development and synthesized that it serves as the building blocks for the generation ofincome and employment. These scholars have presented tourism as one of the most productive business sectors. The ways out as suggested by these scholars include fair distribution of income tothe concerned communities, and preservation and promotion of environmental and cultural heritages in order to ensurethe long-term viability. It also requires adequate and authentic training and education of the business operators as well as consumers. In fact, the tourists need be made aware of the impact of their choices. More importantly, the operational affairs need be promoted through mutual cooperation between stakeholders, businesses, authorities and the tourists to provide for the right framework of operations in action.

The present researcher firmly believes that sustainable mountain tourism development in Nepal, especially in the Khumbu Region, must be considered in respect with its potential to - 1. generate economic viability, 2. empower local prosperity, 3. promote the local employment quality and quantity, 4. promote social equity, 5. reward with visitors' perceived fulfillment, 6. capacitate and maintain local control, 7. promote the community wellbeing, 8 . explore and promote the cultural richness, 9. maintain physical integrity of the locality, 10. promote the development and protection of biological diversity, 11. improve the efficiency of development and consumption of local resources, and 12. contribute significantly in maintaining environmental purity of the destination so as to make the place to be able to keep on appealing the visitors for travel visits time and again in the long-run. The subsequent sub-sections present with the existing reality in respect with these potentialities in the Khumbu Region.

Economic viability serves as one of the key aims of sustainable development of any sector. In mountain tourism, economic viability serves as a backbone to ensure the viability and competitiveness of the tourism destinations and enterprisesso that they can be able to continue to prosper and deliver benefits in longer runs without distorting the natural and social systems.

For example, Neto (2003), in a work aimed at the exploration of a new approach to sustainable tourism development for moving beyond environmental protection, has concluded that the new approaches to sustainable tourism development in the developing world should not only seekto minimize local environmental impact, but also it should give greater priority to communityparticipation and poverty reduction to a greater extent and utmost potential to do so. 
In the context of Khumbu Region, in particular, more emphasis should be givento a 'pro-poor tourism' approach at both the local communities and national levels. The key participant revealed his innocence in confirmation of economic viability of the different development and protection or conservation initiatives carried out by the government and non-government agencies in the region. The participant added, if there was a training and development program being conducted with involvement of the local people and if it concludedwithout conveying a meaningful value how, where and when to implement the ideas evolved or shared during such discourses, it could just establish an example of the wasteof participants' valuable time and involvement nullifying the cost of opportunity. This participant meant to share that each effort vested with an aim to promote sustainable tourism development must first address the ability, willingness and maturity of the larger spectrum of the beneficiary society to move on the expected mission. And, equally important concern is that such initiatives must serve instrumental in generating continued economic means of bread and butter for the target groups in the longer runs.

A more recent work by Shokirov, Abdykadyrova, Dear and Nowrojee (2014)empirically confirmed that a larger segment of population reside in remote, mountainous communities with limited access to general infrastructure, services and opportunities, confirmed the same in UNWTO (2005). As a result, the incomes in such places are low, natural resources are being depleted, and the lack of social and economic assets has forced many people to seek opportunities elsewhere. UNWTO (2005) has identified such rate of outbound migration to be more than $30 \%$ of total population in many places. In the case of Khumbu Region, the key participant reported that most of the youth from many communities, including from the market zones, had already been migrated to either other parts of the country or abroad in search of better opportunities for livelihood.

In course of addressing such an issue more rationally, the poor, remote mountainbased communities must receive a great deal of socio-economic returns by means of each endeavor targeted for sustainable tourism development in the region (Shokirov, Abdykadyrova, Dear, \&Nowrojee, 2014), which in turn, should serve as a developmental resource to confirm sustainability through perceived economic viability and value. This idea matches with the expectation of the key participant of the present researcher.

Local prosperity should be considered as another important aimof sustainable tourism development to maximize the contribution of tourism for the economic prosperity of the host destinations, including the proportion of visitor spending that is retained locally. However, there is hardly some evidence of state contribution to develop adequate infrastructure leading to local prosperity in the present context of Khumbu Region in Nepal.

The key participant exchanged his grief that the government collected revenue from each tourist visiting the Khumbu Region but hardly paid it back to the communities 
for constructing local treks, healthposts, schools and Gumbas - the most essential infrastructures. The key participant revealed, "We are self-generating the electricity and drinking water, and there is not a single contribution by the state to construct the treks and management of sanitation these days.How can we be convinced on government's shared commitment for building and promoting the local prosperity?"At the same time, the participant reported that there existed a highly congenial and shared feeling among the community members for the collective promotion of 'total wellbeing' of the society at large.

In fact, the key participant's claim could be further confirmed by relating it with the evidence of the present researcher's prior learning about the collectivism of the Sherpas in this region. A few years back, almost all households in many remote villages of this region were badly hit by an earthquake and the district administration was so late to respond with immediate action that the situation urged the local communities to come up with their self-initiated moves to collect funds to support the victim households. In an another example, the local community members had raised almost NRs. 500,000.00 to upgrade the infrastructure of local public health center at Namchebazar.

According to Buckley (2012), sustainable tourism development generates a multifold impact on promoting local prosperity in the form of a number of demographic effects that include empowerment of the gender and other roots of diversity, promotion of education and life skills among the local stakeholders, collective participation in conflict negotiation and peace building, increased demand of the locally produced materials, and enterprise development leading to entrepreneurial culture in the remote areas.

Really, it is a matter of pride in the Khumbu Region that the women have been taking leadership in almost all areas of entrepreneurship, social development and other respects. For example, almost three years back, the present researcher got an opportunity to participate in a local women group initiated program on afforestation in the areas of stone-mines nearby Namchebazar. The noble contribution of the women was even appreciated by then Ambassador of India to Nepal, who was the chief guest of its inaugural ceremony. More than 7,000 plants were transplanted in the stone-mined areas, vulnerable for land erosion. The concept was entirely initiated by the local visionary women and a large troop of Nepal Army from SagarmathaNationa Park actively supported in this mission. The local key participant in this respect recalled it as an impact of the Hilarity of the Sherpa spirit on collectivism for positive causes.

Equally, sustainable tourism development in the mountain regions will result in forced development of infrastructure in such disconnected and deprived areas. As sustainable tourism emphasizes innovation and adoption of newer practices, hopefully it may serve instrumental in the promotion of more prosperous human, institutional and rest of environmental livelihood in such destinations (Shokirov et al., 2014; \& Buckley, 2012). 
Other many studies have noted that many mountain communities around the world promoted ecotourism ventures to remodelthe problems of underdevelopment and environmental degradation. However, there is almost no evidence of agreement on what components such missions of tourism development should cover in totality. For example, Nepal (2014) has explored the value of ecotourism in the mountains and found that it would foster responsible tourist behavior, conservation of important wildlife habitats and ecosystems, appreciation of local cultures and traditional lifestyles, and provision of sustainable forms of livelihood for people living in remote areas and communities of such destinations.

In fact, all these behaviors will contribute significantly in leveraging local prosperity in the target locations.More importantly, the mountain tourism destinations in the developed economies are characterized by consolidation of businesses to increase profits and efficiency through reduced management costs and internal structural adjustments which also contribute significantly for the promotion of local and regional prosperity, the scholars have concluded(Buckley, 2012; \& Nepal, 2002).

The key participant of the present researcher too happened to share similar experiences by saying that the people who once did not have money to buya packet of life-saving Jeevanjal, a means of rehydration in times of urgency, at NRs. 40, now the same people were enjoying maintaining bank deposits as provision money to be used in times of such urgency. This all was the outcome of their involvement in tourism activities, according to the key participant, meaning that sustainable tourism development results in creation and promotion of prosperous local livelihood. At the same time, the key participant also regretted about the drifted behavior of thee new generation. He shared, "Sometimes, our youth is seen to be more lured, so quickly. As a result, the negative side of the spirit - the evil side -affects them adversely and the consequences are beyond imagination." "Sometimes the collective purity is helpless to nullify such an individual impurity, in the cases where mostly the younger people expect much higher rewards that what they actually deserve through rational means", exchanged the key participant. This all confirms that the Sherpa spirituality rests on the ground of purity of mind, body and soul, as a whole of spirit.

Employment quality and sustainable tourism development must keep on strengtheningside by side where the number and quality of local jobs created and supported by tourism should witness the same, including the level of pay, conditions of the services and availability to all without discrimination by gender, race, disability, or in other ways.

The key participant's verse in this respect was that though the efforts made so far by the different agencies to promote skill competence and working knowledge among the local people remained quite commendable, still there was a big room for bringing forward the people from remotest areas of the remotes. This person said that there existed a severe geographic remoteness within the remote areas and the people benefiting first were mostly from the market zones in the region. 
Another grievance this person shared was that thedifferent places in the region were left with hardly a few youth of the learning stage for the agencies to train them and guide towards their overall socio-economic prosperity and development. He asked, "To whom would you train as almost all the capable and needy youth have migrated outside?" This question itself seems to be big and challenging enough for the agencies working in this respect.He also added, "We the remaining people of the age are left with hardly business opportunity for about four to five months in a year and we have to survive by doing nothing for remaining period of the year. We need to survive on earnings we make in such a short earning seasonal periods by working for about a quarter of the year and remaining time passes away just idle." Could there be an alternative affordable for these people in this idle time? The present researcher is quite concerned, if something could be done for them to engage in their idle time. Such a situation might have affected the prospect of employment to a greater extent in this region.

In respect with the owner's treatment of the employees in the family managed resorts, hotels and restaurants, the present researcher could find hardly any cases of mishandling the workers. Instead, the junior workers were observed to be treated as close as their own children by the owners and the workers were mostly recognized as the beloved assistants. Both the parties shared with good amount of humor, respect, love and care to each other. This confirms a positive message emerging from the hilarity of the Sherpa spirit again.

Social equityand sustainable tourism must go side by side. Sustainable tourism must be developed and promoted within the premise of social equity seeking a widespread and fair distribution of economic and social benefits from tourism throughout the recipient community, including improving opportunities, income and services available to the poor.Similarly, a share of proceeds or the earnings of such exchanges must be spent on promoting social equity. All geographic segments in the remote communities may not receive equal attention and interest of the visitors. In this context, it becomes a social obligation of the haves communities to take care of the needs of the non-haves communities. The Sherpa spirit also has been widely accepted as a source of such cognition - the purity of thought on socio-economic wellbeing of all.

In this respect too, still there is a lot of work left to be done as the entire region severely lacks an equitable distribution of economic, social and emotional benefits of tourism in the region. The households located in the distant outskirts supply with required workforce and other local means of production but these households get the least benefits of tourism in the region, despite the fact that the local people widely accept the idea of helping the poorer communities. The key participant revealed, "The households aside the treks have become golden pieces and the just behind to them are lying under the shed of the candle. We are simply unable to bring forward the backward segments, and it hurts us a lot as we are Sherpaswho value equitable living, at least among the Sherpa communities." 
Visitor fulfillmentand sustainable tourism development should be considered congruent initiatives. The policies and programs should be initiated keeping in view the priority that the visitors are provided with a safe, satisfying and fulfilling experience, available to all without discrimination by gender, race, disability, or in other ways. For example, there is hardly some scope of free drinking water available for the travelers in the Khumjung Valley, neither there is full coverage of the local resorts and restaurants in all outer catchments. In this respect, the key participant shared the grievance that the district administration at Solukhumbu was neither favoring, nor supporting the local user groups. Despite the release of funds from the capital city, the district administration wasreported to be less cooperative in this respect to release the budget in timely and needful manner. Similar was the case of sanitation. The only public toilet in the Khumjung Valley was in the closed state at the time of present researcher's visit during the peak touristic season in fall 2014.There was a thick, constant smoke coming out of round the clock burning of the solid waste materials disposed at the burning center. Is it an environmentally safe and sustainable idea? In fact, the smoke might have affected adversely the rare wildlife too. The key participant also agreed.

Local controlis another equally important aim of sustainable tourism as it has to be promoted by engaging and empowering the local communities in planning and decision making about the management and future development of tourism in their areas. It can be achieved in consultation with, and direct support of a number of other stakeholders.

The key participant had an adverse experience in respect with national mechanism's readiness to promote local control over resources and procedures of tourism development in the Khumbu Region, especially in respect with the present national policy on utilization of revenues collected by means of tourism accounts.

As it has been already discussed above, the local community severely felt deprived of return of adequate amount of money earned by the state through tourism exchanges in the region. In this respect, the key participant complained, "We generate local resources and construct Gumbas in different places. We have developed aSherpa Museum using a lot of time and efforts. We guide the visitors to the different smaller to larger peaks. They visit all these places as we have maintained them visitable. The state charges a huge amount of money to them for allowing their visits to our places but this money does not come to our hands. The state collects it and hardly gives back for spending on building local infrastructure to appeal more tourists to visit the ountryside destinations. I firmly believe, it is all affecting the natural law of local controlover returns coming from the accounts of tourism here." In fact, this dialectical exchange has a firm rooting with the prevailing poor national policy, structural governance and culture which fails to pay adequate attention with the spirit of federalism. There is an immediate need of effective policy intervention at both national as well as local levels in this respect to empower the hard earners with their control over what they earn in the name of tourism related national accounts. 
Community wellbeingshould be empowered by maintaining and strengthening the quality of life in local communities, including social structures and access to resources, amenities and life support systems, avoiding any form of social degradation or exploitation, as another equally important objective of sustainable tourism development.

More subtly, as stated by Lane (2014), excessive exploitation of tourism can destroy the future it promises by rendering the destination dependent on its dollars, then declaring a spoilt destination unfashionable and redundant. Ineffective operation of the tourism cycle can affect both large resorts and rural retreats, rich and poor countries alike. Tourism is a volatile, fashion industry. So, it needs be well-understood and wellmanaged to confirm its sustainable impacts for the host society and natural setting, at large.

The key participant was concerned in this respect and shared that the Sherpa community was always aware of, and convinced to maintain adequate silence and dignity of destinations. However, this participant had a good reason to oppose the present national policy that allows everybody to climb the peaks. The key participant questioned, "Where remains the dignity of the pure Himalayas, if the state allows every type of person to climb, and in any number every season?" This participant was of the opinion that only a select number of physically, mentally and socially healthy people should be permitted to climb the pure mountainsas it has been considereda part of their spiritual reality. The present researcher is yet to learn a lot in this respect before disclosing on this dimension further for general readers, who otherwise, may be innocent about this reality. The ongoing exploration entitled 'Hilarity of Sherpa Spirit' has a reasonable promise to disclose more on this subject.

Cultural richness has to be promoted as an outcome of sustainable tourism development in the mountains and anywhere else and it should be promoted with respect and enhancementof historic heritage, authentic culture, traditions, values and distinctiveness of the host communities so that each destination will be appealing the visitors in a unique way and in the form of a good memory - the stage of experience.

A scholar in a more recent work feared the consequences of failure to effective management of sustainable tourism development as it can have serious cultural impacts. According to this scholar, the tourists are mostly wealthy and sometimes they have a tendency of acting like demanding guests (Lane, 2014). Their dominant nature may ruin local customs; turn land values and labor markets upside down; make local languages redundant; and shift the balance of political power in favor of distant multi-nationals. In some scenarios tourism can bring vice and crime. In this respect, the actors of tourism development in innocent areas need be much thoughtful.

The key participant reserved that the Sherpa customs and traditions cannot be 
easily affected just as a result of visitor influence as each member of the Sherpa society has grown up with rightly nurtured family and community value systems on gaiety of Sherpa spirit and spirituality. He said,"Our Sherpas rather teach them the core spiritual value systems and Tibetan Buddhism, both of which nurture people towards peace and non-violence."

Physical integrityis another important contribution of sustainable tourism development which is expected to be promoted by maintaining and enhancing the quality of landscapes, both urban and rural, to avoid the physical and visual degradation of the environment.

According to Lane (2014), failure to handle the issue of sustainable tourism development can have powerful physical impacts on touristic destinations - farm and forest landsmay be swept away for airport and road construction, hotels and golf courses - often in scenic regions. Physical impacts can be complex and far-reaching - ski run development clearing trees can open the way to soil erosion, leading to landslides and potential major disasters. Heavily used areas can suffer erosion from sheer numbers of visitors - mountain erosion in the Himalayas arethe classic examples. Whole ecosystems can be damaged, if the players of mountain tourism fail to manage it effectively.

Lane (2014)has further stated that in the recent years, the impact of the transport system as a fundamental means of modernization of tourism has been increasingly recognized.They burn large quantities of fuel in a fuel hungry world; they produce large quantities of emissions in a world beset by climate change issues. On top of it, the climate change and transport issues are major issues that loom over the world of sustainable tourism development.

Many pasture lands in the Khumbu Region are now at a cross-road of devolution as a result of occupational acculturation, urbanization, and outbound migration of the working class people from this region. Development of village resorts, hotels and restaurants in fertile lands has been affecting adversely the rare forms of agriculture and cattle rearing. On top of it, numerous cases of landslides were reported to be taking lives of many people and damaging a lot of other property each year in different parts of the region as a result of poor or inferior landscaping in agricultural lands.

The key participant shared it as a result of failure to maintain adequately required vegetation in the glacier made slopes. There is enormous chance of landslides during the rainy and snowing seasons and the wildlife is equally affected. The key participant envisioned if a share of money collected out of visitor economy could have been spent for this purpose, the high hills would have been made even beautiful to roam around for the visitors and the wild life also would have been improved. 'We are in need of a tangible master plan now', he paused. He was of the opinion that each household must maintain green color tin-roofs; there must be a consensus that each adult member 
living in the society or working there should have a social responsibility of sowing and growing at least ten plants every year; there should be shorter periods of freedom given to the community members for the collection of firewood.

Biological diversityhas been considered as another outcome of sustainable tourism. It is equally important to support the conservation of natural areas, habitats and wildlife, and minimize the damage to them.

Draper (2000, p. 408) has suggested, "As a concept, 'sustainability' refers to the ability of an ecosystem to maintain ecological processes and functions, biodiversity and productivity over time."This scholar has further explained a more pragmatic meaning of 'sustainability' as an understanding what the people must learn how to sustain environmental resources so that they continue to provide benefits to all concerned stakeholders, other living things, and the larger environment of which they are a part. According to this scholar, sustainable tourism must involve balancing approach to social, economic and environmental objectives so that tourism will remain viable in an area for an indefinite period of time.

The key participant, as a popular conservation activist in the region, shared that the community at its best level of experiential and observational learning must be allowed to take the initiatives of their choices in terms of development, protection, promotion and conservation of biodiversity in the region. He suspected that the people walking to the area as the external visitor experts may not know rightly what type of biodiversity would naturally fit in the region. In this respect, he shared that the local people were quite discouraged as there was little recognition and respect of the local indigenous technology and knowhow. He said that the development activists were less patient to listen to the community people. As a result, the efforts initiated for the promotion of biodiversity in the region could not yield the results to the extent of expectation.

Resource efficiencymust be witnessed as an outcome of sustainable tourism development whereby the focus should be on minimized use of scarce and nonrenewable resources in the development and operation of tourism facilities and services. The key participant reported that there was a massive use of firewood in the region. He stated, "It takes about 30-40 years for a pine tree to grow as a mature source for firewood but there has been a massive use of it. Not only firewood, pine is only the source for infrastructure construction in the region." It can be openly observed inmany areas that the people keep huge piles of firewood. The local administration and user groups allowpeople to collect the firewood once or twice a year. Similarly, the human settlements require a lot of pinewoods for construction purpose.

There is urgency of enactment of an alternative strategy. Especially, the general public and business institutions operating in the localities of Khumbu Region have been facing a daunting task of identifying suitable and feasible alternatives in respect 
with the arrangement of 'fuel for fire' which is one of the noble means of living in the society.

Environmental purityshould be considered on top of above all as the idea of sustainable tourism development aims to minimize the pollution of air, water and land and the generation of waste by tourism enterprises and visitors.

The key participant at Khumjung Valley shared, "Look, in our early days, there was little forest here around our villages but today we have grown a lot of them. It is a great success in this glacier valley. We have done it. But one problem always rings in my mind. That is - in early days there used to roam around a number of wild animals in this area but today our children cannot see any of them, any time."

In fact, there could be at least three main reasons behind it -- 1 . the localities have converted to crowd, 2 . there is constant burning of waste materials in different places in each community zone, and/or 3. the animals might have disappeared due to illegal poaching. There has appeared an anomaly; despite the community success in growing green forests, the wild life has been declining in the region.

The root of the problem may be residing within the level of intensity and diversity of tourism initiatives causing the environmental purity that the local community and respective stakeholders are capable of maintaining in their own. For example, the noise and air pollution are increasing day by day - both generating fear for the wild life. Some quick alternatives are needed.

The Department of Economic Affairs, Agriculture and Tourism, Provincial Administration of the Western Cape (2001) made a significant landmark in sustainable tourism development in the Western Cape areas by inducing more pragmatic and participatory policies with defined roles, duties and accountabilities of the civil society, conservation activists, and local, regional and central government structures.National and regional level administration has been sought with responsibility of development and enactment of relevant policy guidelines, whereas the local community stakeholder groups are made responsible for an effective implementation of such policies in action. This could serve as a best practice for Nepal.

\section{Conclusion}

As a purely independent and indigenous practice, the tourism industry, in any context, should not be governed either by the government or the market forces injected from outside. To achieve a more sustainable form of tourism, it should rather be successfully driven by self-regulation as being the best way forward for rest of the world.

The above all discussions confirm that the sustainable mountain tourism development in the Khumbu Region should be initiated not just by planning for tourism, but also by integrating tourism into a balanced and futuristic relationship with broader socio-economic, cultural and heritage development interventions in the 
region. That is the way in which sustainable tourism fulfils its requirement to think holistically as an integral part of social life in the region. In many rural areas the watchword is that the mountain tourism should be a tool for rural natural and heritage conservation, service retention and diverse development. However, there is a key caveat -- sustainable development cannot be created by planning alone, it needs be worked in line with the marketand local ground realities.

The ground reality is that the mountains are melting. The fires are burning everywhere. The forests are cut down. Pasturelands are being cultivated. People are migrating. Mobilization of the earning from tourism has been centralized. And many more are the anomalies. All what the entire region of Khumbu requires is a swift, collective, proactive and reactive move.

Sometimes, if things do not move as expected, the state mechanism should regulate them rather than creating coercion or imposing explicit measures which the community would be in other way position of their implementation. Equally important aspect is that the public settlements in the mountain regions of Nepal are still innocent of market intelligence and as a result, they may vulnerable to be abused by the so called intelligent and tactful people from other places. For example, Buckley (2012) has revealed that some tourism advocates still use the political approaches to avoid environmental restrictions and to gain access to public natural resources. In this context, the state machinery should take it into consideration to provide with such a regulation that the indigenous people of this region should find themselves proud of being the natives of the Khumbu Region.

The tourism researchers must consider socio-cultural and environmental issues as integral components of their inquiry in every type of research conducted. Moreover, the universities and higher education institutions should consider the ground realitybased requirement of training and development of the people and institutions living and working in such regions keeping in mind the broader sustainability as a lasting outcome of any initiative undertaken.

\section{References}

Bertels, S., Papania, L., \&Papania, D. (2010). Embedding Sustainability in organizational culture - a systematic review of the body of knowledge.Simon Fraser University. Network for Business Sustainability.

Buckley, R. (2012). Sustainable tourism: research and reality. Annals of Tourism Research, 39, 2, 528-546. Printed in the Great Britain.

Castellani, V., \&Sala, S. (2009). Sustainable tourism as a factor of local development.United Nations World Tourism Organization [UNWTO].

Chowdhury, U. K. (2013).Tourism next in Nepal vision ahead.Business Age. 13 (2), November 2013. 
Department of Economic Affairs, Agriculture and Tourism, Provincial Administration of the Western Cape.(2001). Whitepaper on sustainable tourism development and promotion in the Western Cape. Western Cape: Author.

Jack, G., \& Phipps, A. (2005).Tourism and intercultural exchange: why tourism matters. Clevedon: Channel View Publications.

Keelson, S. A. (2012).The evolution of the marketing concepts: theoretically different roads leading to practically same destination.Online Journal of Social Science Research, 1, 2, 35-41. April 2012. Available at: http://www.onlineresearchjournals.org/ jss. Retrieved on: November 6, 2014.

Klaztzel, F. (Edited). (2011). Stories and customs of the Sherpas.[As told by Tengboche Rinpoche, and Nawang Tenzin Zangbu].Kathmandu: Mera Publications.

Klaztzel, F. (2009).Gaiety of spirit: the Sherpas of Everest. Kathmandu: Mera Publications.

Korèekovã, V., Pasca, A., \&Rouby, A. (2014).Background paper on sustainable mountain tourism. Euromountain Secretariat. Available at: http://www.euromontana.org/wpcontent/uploads/backgroundpaper_Iverness.pdf. Retrieved on: November 3, 2014.

Kotler, P., \& Armstrong, G. (2009).Principles of marketing. (12 $\left.{ }^{\text {th }} \mathrm{ed}.\right)$. New Delhi: Pearson Education.

Kunwar, R. R. (2010). Tourists and tourism: science and industry interface. Kathmandu: Ganga SenKunwar.

Kunwar, R. R. (1999). Fire of Himal: an anthropological study of the Sherpas of Nepal Himalayan region. ( $2^{\text {nd }}$ ed.). Kathmandu: Nirala Publications.

Lane, B. (2014). Sustainable development and sustainable tourism: business, the community and the environment. Available at: www.caribbeanstc.com/wpcontent/.../Notes-Sustainable-Tourismapr10.doc. Retrieved on: November 4, 2014.

Lovelock, C., Wirtz, J., \&Chatterjee, J., (2011).Service marketing: people, technology, strategy. ( $7^{\text {th }}$ ed.). New Delhi: Pearson Education.

McMinn, S. (1997).The challenges of sustainable tourism.The environmentalist. 17, 135-141. Ontario, Canada.

National Planning Commission [NPC].(2012). Nepal status paper.United Nations Conference on Sustainable Development 2012 (Rio + 20).Government of Nepal: Author.

Nepal, S. K. (2002). Mountain ecotourism and sustainable development: Ecology, economics, and ethics.Journal of Mountain Research and Development.May 2002, pp. 104-109. British Colombia, Canada: International Mountain Society. Available at: http://www.bioone.org/doi/abs/10.1659/0276-4741(2002)022\%5B0104:MEASD\% 5D2.0.CO\%3B2. Retrieved on November 4, 2014. 
Neto, F. (2003).A new approach to sustainable tourism development: moving beyond environmental protection. A United Nations DESA discussion paper, March 2003.Available at: http://www.un.org/esa/papers.htm. Retrieved on November 1, 2014.

Pine II, B. J., Gilmore, J. H. (1998). Welcome to the experience economy. Harvard Business Review, July - August 1998, pp. 97-105.

Raasch, U. (2004). Interpretation as a visitor management tool in national parks - a case study of Jasmund National Park on the Island of Rügen, Germany. An unpublished Masters degree dissertation, Bournemouth University.

Rijal, C. P. (2014). Rijal on service marketing: a graduate study manual. Kathmandu: Author.

Rijal, C. P. (2014).A concept note on establishing an autonomous institution for hospitality studies in Nepal.NATHM Souvenir.Kathmandu: Nepal Academy of Tourism and Hotel Management (NATHM).

Rijal, C. P. (2011). Leadership readiness - a road to total quality management (TQM) implementation. Germany: Lambert Academic Publication.

Schorner, B. (2011). Sustainable mountain tourism development illustrated in the case of Switzerland. SPNHA Review, volume 6, issue 1. Grand Valley State University, Switzerland.

Shokirov, Q., Abdykadyrova, A., Dear, C., \&Nowrojee, S. (2014). Mountain tourism and sustainability in Kyrgyzstan and Tajikistan: a research review. Background Paper, No. 3, July 2014. University of Central Asia, Mountain Societies Research Institute.

Thierstein, A., \&Walser, M. (2000).The sustainable region: a model for action. (vol. 1).Institute for Public Services and Tourism Contributions to the Regional Economy, Switzerland.

United Nations Environment Program [UNEP] and United Nations World Tourism Organization [UNWTO]. (2005). Making tourism more sustainable - a guide for policy makers. Available at: http://sdt.unwto.org/content/about-us-5.Retrieved on: November 10, 2014.

United Nations Organization [UNO]. (1992). United nations conference on environment and development.Rio de Jenerio, Brazil, 3 to 14 June 1992. Washington DC: Author.

World Tourism Organization [WTO]. (2005). Making tourism more sustainable: a guide for policy makers. A joint publication of United Nations Environment Programme(UNEP) and World Tourism Organization (WTO).Available at: http://www.unep.fr/shared/publications/pdf/DTIx0592xPA-TourismPolicyEN.pdf. Retrieved on: 1 November, 2014.

Zurick, D. N. (1992).Adventure travel and sustainable tourism in the peripheral economy of Nepal.Department of Geography and Planning, Eastern Kentucky University, Annals of the Association of American Geographers. 